Check for updates

Cite this: RSC Adv., 2018, 8, 11975

\title{
Surfactant-assisted synthesis of Mo-V mixed oxide catalysts for upgraded one-step conversion of glycerol to acrylic acid $\uparrow$
}

\begin{abstract}
Letícia F. Rasteiro, (D) Luiz H. Vieira, (D) Celso V. Santilli (D) and Leandro Martins (D)*
The catalytic properties of Mo-V mixed oxides hydrothermally synthetized in the presence of ionic surfactants (SDS and CTAB) were investigated in the gas-phase oxidative dehydration of glycerol. The presence of surfactants promoted a change in morphology of $\mathrm{MoV}_{2} \mathrm{O}_{8}$ phase, directing to formation of rod-shaped crystals, and, consequently, an increase in macroporosity of materials, generated by intercrystallite spaces, when compared to a reference sample. Rod-like morphology stabilized the $\mathrm{MoV}_{2} \mathrm{O}_{8}$ mixed oxide phase during glycerol conversion, avoiding migration of vanadium from crystalline to amorphous phase, like observed in the reference sample, favoring the dynamic of reduction/ reoxidation of vanadium and, consequently contributing to an increase in efficiency and stability of the catalyst. Both SDS and CTAB catalysts presented higher productivity of acrylic acid and good catalytic stability, with no coke formation and considerable decrease in $\mathrm{CO}_{x}$ evolution during $6 \mathrm{~h}$ of reaction. SDS presented the best catalytic results with $100 \%$ of conversion, $57 \%$ of acrylic acid selectivity and $36 \%$ of $\mathrm{CO}_{\mathrm{x}}$ selectivity.
\end{abstract}

Received 14th February 2018

Accepted 21st March 2018

DOI: $10.1039 / \mathrm{c} 8 \mathrm{ra01443d}$

rsc.li/rsc-advances

one catalyst with bifunctional properties is getting more attention due to several advantages. ${ }^{15}$ Mixed oxides based on molybdenum and vanadium, $\mathrm{Mo}_{x} \mathrm{~V}_{y} \mathrm{O}_{z}$, are prominent catalysts to perform the one-step conversion of glycerol due to the moderate acidity and well-known oxidative potential of vanadium in these structures, conducted by the Mars-van-Krevelen mechanism. ${ }^{\mathbf{8} 16}$ However, the main disadvantages of these catalysts are the textural properties, like low specific areas and porosity, ${ }^{8,17-19}$ and the instability of the mixed oxide phases in the reaction conditions. ${ }^{20}$ The solid-state reaction and/or spreading of mixed oxide phases when applied in catalytic systems under high temperatures and oxidant atmospheres can lead to a restructuration of phases ${ }^{20}$ to form single component oxides and/or migration of active species to amorphous phase.

The use of surfactants in the synthesis of catalysts is a method to create porous structures in the material and/or to alter surface characteristics. ${ }^{\mathbf{2 1 , 2 2}}$ The addition of surfactants in the synthesis of $\mathrm{Mo}_{x} \mathrm{~V}_{y} \mathrm{O}_{z}$ can bring new textural properties and lead to a stabilization of the mixed oxide phases in these catalysts, not yet studied. the second stage, the oxidation of acrolein to acrylic acid occurs on metal-oxygen redox sites. ${ }^{\mathbf{1 4}}$ Therefore, for the selective synthesis of acrylic acid from glycerol, the catalysts need to possess acid and oxidant sites. ${ }^{\mathbf{1 2}}$ This route of glycerol valorization can be performed with one or two catalysts, but the use of

Instituto de Quimica, Unesp - Universidade Estadual Paulista, Rua Prof. Francisco Degni 55, CEP 14800-900 Araraquara, SP, Brazil. E-mail: leandro@iq.unesp.br

$\dagger$ Electronic supplementary information (ESI) available. See DOI: 10.1039/c8ra01443d

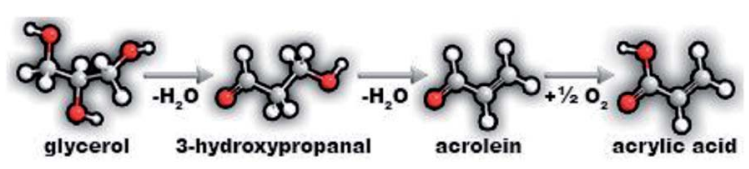

Scheme 1 Two-step glycerol oxydehydration: dehydration to acrolein followed by oxidation of acrolein to acrylic acid. 
In a previous work, we studied the effect of synthesis and calcination atmospheres in the formation of Mo-V mixed oxides crystalline phases prepared by a hydrothermal method and evaluated their performance in the one-pot glycerol oxydehydration to acrylic acid. ${ }^{6}$ We identified the $\mathrm{MoV}_{2} \mathrm{O}_{8}$ and $\mathrm{Mo}_{4.65} \mathrm{~V}_{0.35} \mathrm{O}_{14}$ as the most active phases in the reaction but with low stability during reaction. Herein, we describe the surfactant-assisted synthesis and structural characterization of $\mathrm{Mo}_{x} \mathrm{~V}_{y} \mathrm{O}_{z}$ catalysts and explore how the presence of SDS and CTAB surfactants in the synthesis mixture influences the composition of phases, porosity, crystal morphology, and catalytic activity of these materials in the one-step oxidative dehydration of glycerol.

\section{Experimental}

\section{Hydrothermal synthesis of the Mo-V mixed oxides}

The synthesis of the mixed oxides was performed based on a hydrothermal method described in our previous work. ${ }^{6}$ In a typical synthesis, vanadyl sulfate $\left(\mathrm{VOSO}_{4}\right)$ and ammonium paramolybdate $\left(\left(\mathrm{NH}_{4}\right)_{6} \mathrm{Mo}_{7} \mathrm{O}_{24} \cdot 4 \mathrm{H}_{2} \mathrm{O}\right)$ were dissolved separately in distilled water. Both mixtures were maintained under stirring for $10 \mathrm{~min}$ at $25^{\circ} \mathrm{C}$ and after the complete dissolution, they were mixed and stirred for another $10 \mathrm{~min}$ at $25{ }^{\circ} \mathrm{C}$, resulting in a solution with a $\mathrm{pH}$ of 2.8 and a $\mathrm{Mo} /(\mathrm{Mo}+\mathrm{V})$ mole ratio of $0.60 .^{6,8}$ The mole proportion of the reagents was $1 \mathrm{VOSO}_{4}: 0.2$ $\left(\mathrm{NH}_{4}\right)_{6} \mathrm{Mo}_{7} \mathrm{O}_{24} \cdot 4 \mathrm{H}_{2} \mathrm{O}: 300 \mathrm{H}_{2} \mathrm{O}$. Afterwards, sodium dodecyl sulfate (SDS) or cetyltrimethylammonium bromide (CTAB) were added to the solution and maintained under stirring for $40 \mathrm{~min}$ at $25{ }^{\circ} \mathrm{C}$. The mole ratio surfactant/(Mo $\left.+\mathrm{V}\right)$ was 0.10 . Later, the solution was transferred to a $50 \mathrm{~mL}$ Teflon vessel contained in a stainless steel autoclave reactor, occupying approximately $70 \%$ of the vessel capacity. The reactor was hermetically closed and then purged with pure $\mathrm{O}_{2}$ in successive cycles and finally was pressurized with $\mathrm{O}_{2}$ to 6 bar. The reactor was placed in a glycerol bath heated at $160{ }^{\circ} \mathrm{C}$ and kept for $48 \mathrm{~h}$ under static conditions. The precipitate was separated by centrifugation and dried at $60{ }^{\circ} \mathrm{C}$ for $12 \mathrm{~h}$. The resulting catalyst precursors were heat treated in oxidant atmosphere at $500{ }^{\circ} \mathrm{C}$ during $2 \mathrm{~h}$. The sample synthesized in the absence of surfactant was named reference and samples synthesized in the presence of SDS and CTAB were named SDS-0.10 and CTAB-0.10, respectively.

\section{Characterization}

The amounts of $\mathrm{V}$ and Mo present in the synthesis solutions (mother liquors) were determined by chemical analysis by using an Optima 8000 ICP-OES spectrometer. The amounts of $\mathrm{V}$ and Mo present in the solid catalysts were determined by mass balance between the initial quantities fed into the hydrothermal reactor and those obtained by chemical analysis.

Crystalline phases of the catalysts, before and after the catalytic reaction, were assessed by X-ray diffraction (XRD) using a Rigaku Miniflex 600 diffractometer with $\mathrm{CuK} \alpha$ radiation $(0.15418 \mathrm{~nm})$ selected with a curved graphite monochromator. Data were collected in the $2 \theta\left(^{\circ}\right)$ range from 5 to 60 , with a scan step of 0.02 and counting time of $1 \mathrm{~s}$. All the crystalline phases in the samples were identified with Crystallographica Search Match software and quantified by the Rietveld refinement method using TOPAS $® 4.2$ software. The occupancy and temperature factors of all atoms were fixed, unit cell parameters, scale factor and atomic positions (except for special positions: $0,1 / 4,1 / 3,1 / 2$ etc.) were refined. Sample displacement, zero error and intensity corrections (Lorentz and polarization factors were fixed in 26.4, characteristic value for graphite monochromators) were refined. The background was fitted using a sixth-order Chebyshev polynomial function. Fundamental parameters profile fitting (FPPF) were used for the peak profile refinements.

Specific BET area of the samples were determined by nitrogen sorption measurements performed at liquid nitrogen temperature $\left(-196^{\circ} \mathrm{C}\right)$, with relative pressure interval between 0.001 and 0.998, using a Micromeritics ASAP 2010 system. The samples were pre-treated under vacuum $\left(\sim 10 \times 10^{-6} \mathrm{~Pa}\right)$ for $12 \mathrm{~h}$ at $200{ }^{\circ} \mathrm{C}^{23}$

Density of the samples was evaluate by helium pycnometry using a Micromeritics AccuPyc 1330 and then transferred to a Micromeritics GeoPyc 1360 to evaluate the total porosity of the samples.

$\mathrm{Hg}$ intrusion porosimetry was used to evaluate the textural characteristics of the materials in the macro- and mesopore ranges. The measurements were carried out in a Micromeritics Autopore III equipment, operating for the determination of pores with a minimum diameter of $3 \mathrm{~nm}$. The pore diameter was calculated by means of the Washburn equation $(r=$ $-2 \gamma \cos \theta / P)$, using surface tension and contact angle values of $0.489 \mathrm{~N} \mathrm{~m}^{-1}$ and $135^{\circ}$, respectively.

Particle size and shape of the catalysts were observed by SEM images on a FEI Magellan 400L microscope. Samples were previously deposited on an aluminum sample holder and subsequently sputtered with gold for $30 \mathrm{~s}$.

Thermogravimetric analysis (TGA) of the spent catalysts was conducted under a flow rate of $100 \mathrm{~mL} \mathrm{~min}^{-1}$ of $\mathrm{O}_{2}$, using an SDT Q600 TGA/DSC thermobalance, with a heating rate of $10{ }^{\circ} \mathrm{C} \mathrm{min}$ m $^{-1}$ from 30 to $600{ }^{\circ} \mathrm{C}$.

Acid sites of the Mo-V mixed oxides were measured by temperature programmed desorption of ammonia (TPD- $\mathrm{NH}_{3}$ ). In these experiments, a mass of $200 \mathrm{mg}$ of sample was placed under a He flow $\left(60 \mathrm{~mL} \min ^{-1}\right)$ at $300{ }^{\circ} \mathrm{C}$ for $1 \mathrm{~h}$, followed by cooling to $100{ }^{\circ} \mathrm{C}$. At this temperature, the sample was exposed

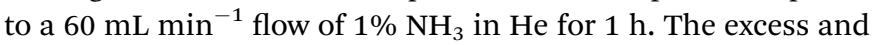
physically adsorbed $\mathrm{NH}_{3}$ was then purged at $100{ }^{\circ} \mathrm{C}$ under a flow of He during $60 \mathrm{~min}$. Finally, ammonia was desorbed in a $\mathrm{He}$ flow of $60 \mathrm{~mL} \mathrm{~min}{ }^{-1}$, with heating from 100 to $500{ }^{\circ} \mathrm{C}$ at a rate of $10{ }^{\circ} \mathrm{C} \mathrm{min}^{-1}$. The amount of desorbed ammonia per gram of catalyst was calculated from measurements made using a mass spectrometer (PrismaPlus QMG 220, Pfeiffer).

XPS measurements of the catalysts were performed using a UNI-SPECS UHV spectrometer with $\mathrm{Mg}$-K $\alpha$ source $(\lambda=1253.6$ $\mathrm{eV}$ ), pass energy of $10 \mathrm{eV}$, and $0.2 \mathrm{eV}$ energy step. The pelleted samples were first left overnight under vacuum $\left(<3.7 \times 10^{-11}\right.$ $\mathrm{Pa}$ ), after which the analysis was performed at a residual pressure below $3.7 \times 10^{-11} \mathrm{~Pa}$ inside the chamber. The binding energies of the chemical elements were determined by fitting 
the measured spectra and referencing to the C1s $(285.1 \mathrm{eV})$ peak, with accuracy of $\pm 0.1 \mathrm{eV}$. The fitting of the curves was performed with CasaXPS software, using the Shirley baseline function and Voigt profile (70\% Gaussian and 30\% Lorentzian).

The critical packing parameters or shape factors $(g)$ of CTAB and SDS surfactants were calculated according to eqn (1):

$$
g=v / a_{0} l_{\mathrm{c}}
$$

where $v$ is the volume of hydrophobic portion of the molecule, $a_{0}$ is the optimum head group area and $l_{\mathrm{c}}$ is the critical length of hydrophobic tail. The area of head groups, $a_{0}$, for micelles of CTAB and SDS in an aqueous solution are 0.64 and $0.62 \mathrm{~nm}^{2}$, respectively. ${ }^{\mathbf{2 4 2 5}}$ The volume and length of hydrophobic tails were calculated by eqn (2) and (3), respectively:

$$
\begin{gathered}
v=\left(27.4+26.9 n_{\mathrm{c}}^{\prime}\right) \times 10^{-3} \mathrm{~nm}^{3} \\
l_{\mathrm{c}}=0.15+0.1265 n_{\mathrm{c}}^{\prime} \mathrm{nm}
\end{gathered}
$$

where $n_{c}^{\prime}$ is one less than the total number of carbons in the surfactant tail, $n_{\mathrm{c}}$, since the first carbon after the head group is highly solvated and is considered part of it. ${ }^{26}$

\section{Glycerol oxydehydration}

The catalytic reaction was conducted in the gas phase at $320^{\circ} \mathrm{C}$, under atmospheric pressure and using a fixed bed reactor. Firstly, $200 \mathrm{mg}$ of the calcined catalyst was supported on a glass wool placed inside the reactor. The reactor was heated to the reaction temperature under a flow of $30 \mathrm{~mL} \mathrm{~min}^{-1}$ of $100 \%$ of $\mathrm{O}_{2}$ and maintained at this temperature for $15 \mathrm{~min}$ before initiating the reaction. An aqueous solution containing $10 \mathrm{wt} \%$ of glycerol (Sigma-Aldrich, 99\%) was fed to the reactor at a flow rate of $0.05 \mathrm{~mL} \mathrm{~min}^{-1}$. The gas composition was glycerol/ oxygen/water $=2 / 28 / 70$ ( $\%$ mole). The products outflowing the reactor were condensed in a gas-liquid separator kept at $1{ }^{\circ} \mathrm{C}$ and aliquots were withdrawn at every $1 \mathrm{~h}$. A previous test was performed to confirm the efficiency of the condensation and the full recovery of the condensable products outflowing the reactor, by injecting an aqueous solution containing $10 \mathrm{wt} \%$ of acetaldehyde (i.e. the most volatile product detected, with a boiling point of $20^{\circ} \mathrm{C}$ ) into the reactor and determining the mass balance in the gas-liquid separator. The products were quantified using a gas chromatograph (Shimadzu GC-2014) equipped with a capillary column (RTX-1, $30 \mathrm{~m}, 0.32 \mathrm{~mm}, 1$ $\mu \mathrm{m}$ ) and a flame ionization detector (FID). As part of the products was converted to $\mathrm{CO}$ and $\mathrm{CO}_{2}$ and the FID detector is not able to detect them, the produced $\mathrm{CO}_{\mathrm{X}}\left(\mathrm{CO}+\mathrm{CO}_{2}\right)$ was determined by mass balance with the liquefied products. The quantification of the products was done by adding a known mass of $n$-butanol as an internal standard before each injection and comparing with calibration curves of the products.

The glycerol conversion $\left(X_{\mathrm{gl}}\right)$ and selectivity of products $\left(S_{i}\right)$ were calculated according to eqn (4) and (5), respectively.

$$
\begin{gathered}
X_{\mathrm{gl}}(\%)=\left[\left(n_{\mathrm{gl}}^{\text {input }}-n_{\mathrm{gl}}^{\text {output }}\right) / n_{\mathrm{gl}}^{\text {input }}\right] \times 100 \\
S_{i}(\%)=\left[n_{i} /\left(n_{\mathrm{gl}}^{\text {input }}-n_{\mathrm{gl}}^{\text {output }}\right)\right] \times\left(z_{i} / z_{\mathrm{gl}}\right)
\end{gathered}
$$

where $n_{\mathrm{gl}}^{\text {input }}$ and $n_{\mathrm{gl}}^{\text {output }}$ are the molar flow rates of glycerol in the input and in the output ( $\mathrm{mol} \mathrm{min}^{-1}$ ), $n_{i}$ is the molar flow of product $i, z_{\mathrm{gl}}$ is the number of carbon atoms in the glycerol molecule, and $z_{i}$ is the number of carbon atoms in the products. $^{27}$

\section{Results and discussion}

The hydrothermal synthesis procedure allowed a very high solid yield to be obtained, with consequently a high assimilation of molybdenum of $98.8 \%$ and vanadium of $97.3 \%$ in the catalysts. ${ }^{6}$ In fact, by visual observation, the mother liquor was very clear and therefore qualitatively free from reactants.

The diffraction patterns (Fig. 1) show that despite the use of the surfactants in the syntheses, the formed $\mathrm{Mo}_{x} \mathrm{~V}_{y} \mathrm{O}_{z}$ crystalline phases are essentially the same, i.e. $\mathrm{Mo}_{4.65} \mathrm{~V}_{0.35} \mathrm{O}_{14}, \mathrm{MoV}_{2} \mathrm{O}_{8}$ and $\mathrm{MoO}_{3}$ (Table $\mathrm{S} 1 \dagger$ ). The results obtained by X-ray diffraction suggests that vanadium in crystalline phase was incorporated in the mixed oxide structures, since no peaks referent to crystalline $\mathrm{V}_{2} \mathrm{O}_{5}$ were identified. Table 1 shows the textural and surface properties of the mixed oxides, BET area, pore volume, porosity and surface acidity. The use of both surfactants increased the

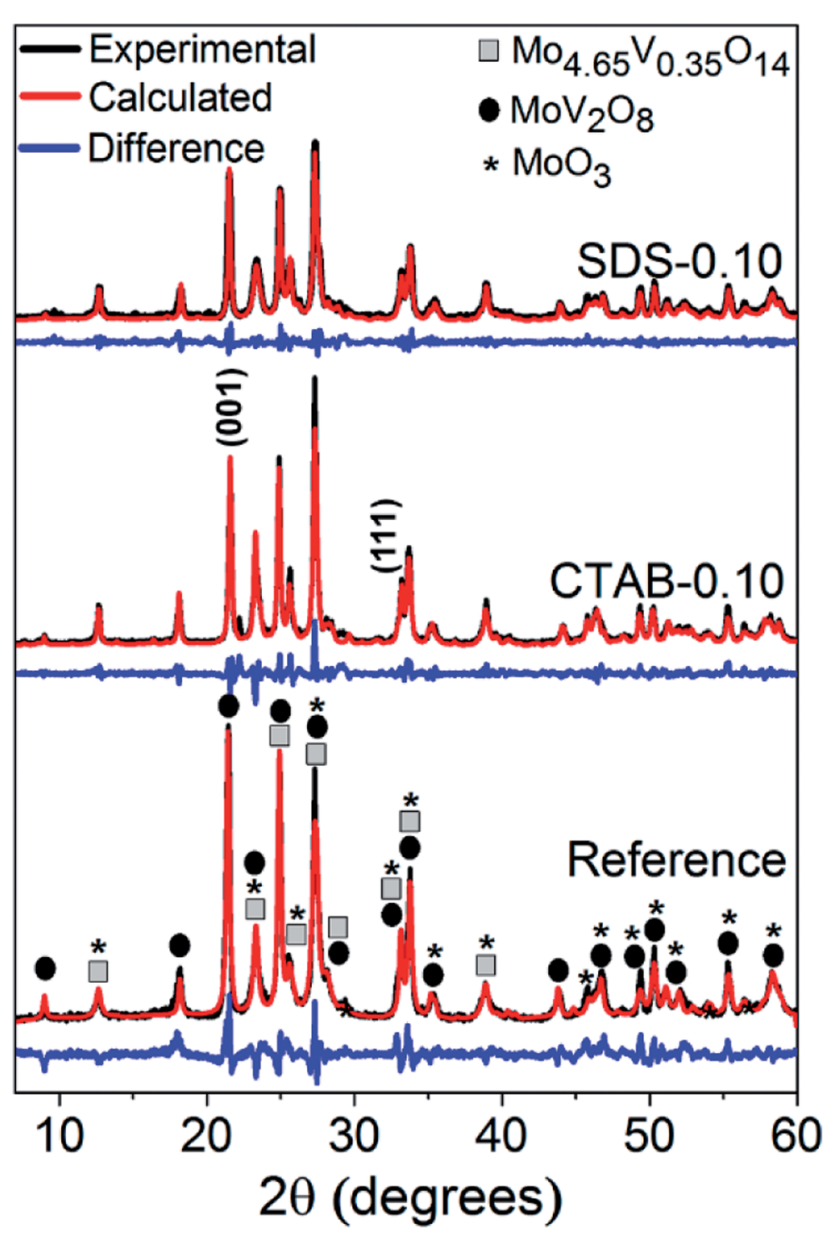

Fig. 1 XRD patterns and identification of phases for the Mo-V mixed oxides. The net results of the Rietveld analyses are shown in red and the deviations from the measured diffractograms are depicted in blue. 
Table 1 Textural and acidic properties of the Mo-V mixed oxides

\begin{tabular}{|c|c|c|c|c|c|c|c|}
\hline Catalyst & $\begin{array}{l}\text { Porosity }{ }^{a} \\
(\%)\end{array}$ & $\begin{array}{l}\text { Pore volume } \\
\left(\mathrm{cm}^{3} \mathrm{~g}^{-1}\right)\end{array}$ & $\begin{array}{l}\text { BET area } \\
\left(\mathrm{m}^{2} \mathrm{~g}^{-1}\right)\end{array}$ & $\begin{array}{l}\text { Chemisorbed } \\
\mathrm{NH}_{3}\left(\mu \mathrm{mol} \mathrm{g}{ }^{-1}\right)^{c}\end{array}$ & $\begin{array}{l}\text { XRD } \\
\text { intensity }^{d}\left(I_{001} / I_{111}\right)\end{array}$ & $\begin{array}{l}\mathrm{MoV}_{2} \mathrm{O}_{8} \text { crystallite } \\
\operatorname{size}^{e}(\mathrm{~nm})\end{array}$ & $\begin{array}{l}\text { Critical packing } \\
\text { parameter }^{f}(g)\end{array}$ \\
\hline Reference & 69.3 & 0.22 & 11.4 & 38.9 & 3.51 & $41.0 \pm 1.3$ & - \\
\hline SDS-0.10 & 82.7 & 1.21 & 1.4 & 27.0 & 5.37 & $88.5 \pm 7.7$ & 0.34 \\
\hline
\end{tabular}

${ }^{a}$ Determined by He-pycnometry. ${ }^{b}$ Determined by Hg-porosimetry. ${ }^{c}$ Determined by TPD-NH ${ }_{3}{ }^{d}$ Intensity ratio of (001) and (111) crystalline plans from $\mathrm{MoV}_{2} \mathrm{O}_{8}$ phase. ${ }^{e}$ Determined by LVol-IB of full peak profile from Rietveld analysis performed on TOPAS V4.2 software. ${ }^{f}$ Critical packing parameter values are referent to surfactant micelles formed in the synthesis mixture.

porosity and the open pore volume as evidenced by Hepycnometry and $\mathrm{Hg}$-porosimetry measurements, but no changes in the BET area of catalysts were noted by $\mathrm{N}_{2}$ physisorption measurements, indicating that the presence of surfactants during synthesis are considerable influencing the porosity in a macropore scale but not generating mesoporosity in the materials. The catalyst SDS- 0.10 had the best improvement in porosity from $69.3 \%$ in the reference sample to $82.7 \%$. In fact, the Hg-intrusion curves in Fig. $2 \mathrm{~A}$ show that SDS-0.10 presented a higher pore volume and a narrower pore size distribution when compared with CTAB-0.10 and the reference samples, with a maximum point at, approximately, $1 \mu \mathrm{m}$.

Additional differences have arisen from scanning electron microscopy images in Fig. 2B, in which nanorod crystals could be clearly observed from very dispersed fragments in CTAB-0.10 and SDS-0.10 samples. The use of both surfactants drastically changed the shape of crystals during synthesis when compared to the reference sample, leading to the formation of randomly stacked nanorods. Considering surfactant-assisted synthesis of materials, the kind and shape of the crystals obtained are directly dependent from type and concentration of surfactant present in the synthesis solution. ${ }^{28}$ We tried to perform the syntheses with lower concentration of surfactants, below the critical micelle concentration (CMC), however, in this condition, changes in the crystal shape were not observed, probably explained by the non-effective micelle formation, and the presence of surfactant only as isolated molecules, as already reported. ${ }^{28}$ In this work, the surfactant concentration used in the synthesis mixture was, approximately, $44 \mathrm{mM}$, a value higher than the CMC of CTAB and SDS in water, of 0.9-1.0 and $8.2 \mathrm{mM}$, respectively. ${ }^{29,30}$ The formation of rod-like crystals in the presence of CTAB and SDS ionic surfactants was already reported in the synthesis of other materials. ${ }^{31}$ The shape factor or critical packing parameter $(g)$ values for these surfactants (Table 1), calculated from head group area, tail length and volume of hydrophobic portion (Scheme $2 \mathrm{~A}$ and eqn (1)), are in the range expected for the structure aggregation to form cylindrical or rod-shaped micelles, ${ }^{26}$ and the result fits well with that observed experimentally. The presence of the rod-shaped micelles limits the crystal nucleation on lateral crystalline plans, which favours a preferential growth in the direction normal to the surfactant free surface (Scheme 2A). ${ }^{32}$ Carefully

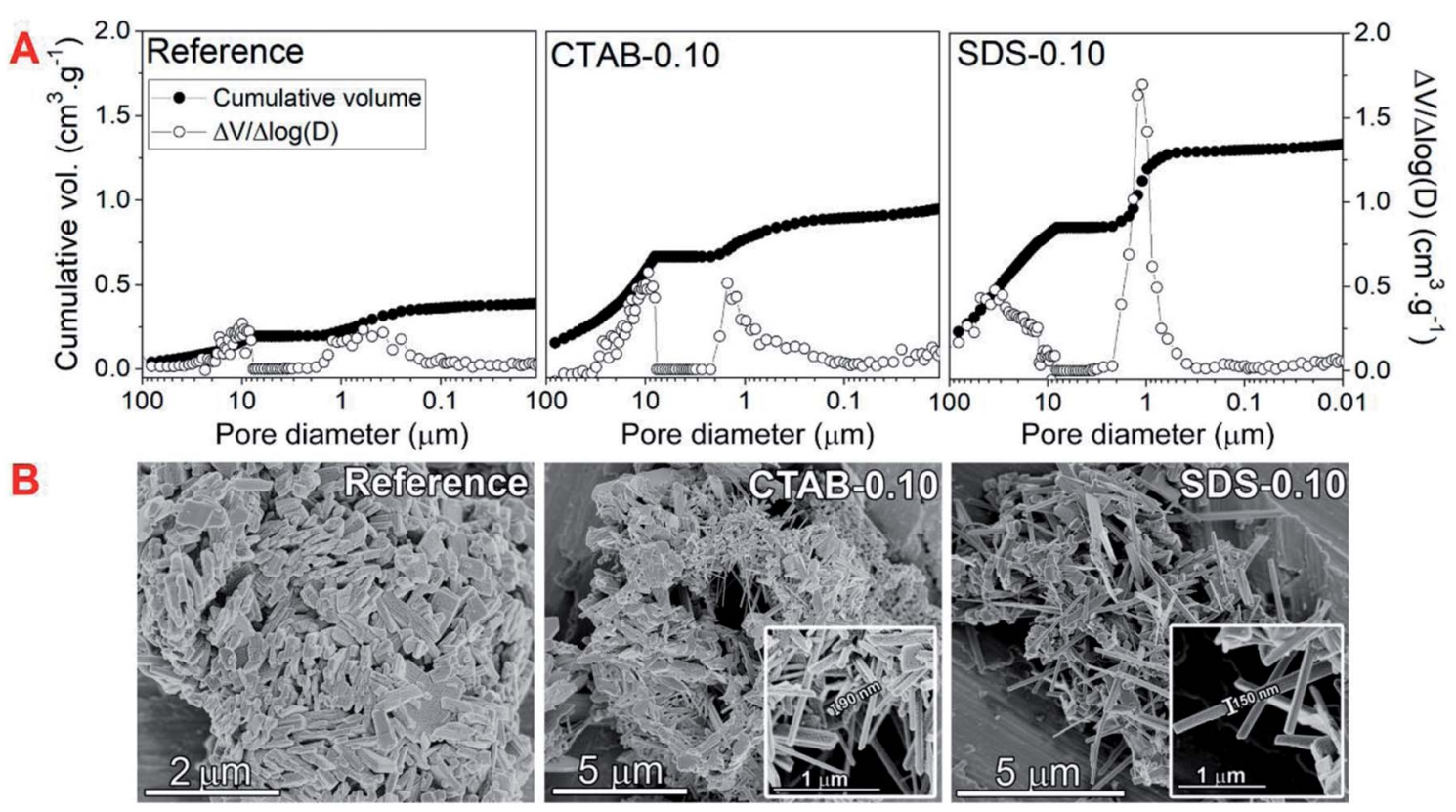

Fig. 2 (A) Representation of ionic surfactant preferentially adsorbed on the side planes of $\mathrm{Mo}_{x} \mathrm{~V}_{y} \mathrm{O}_{z}$ crystal leading the nanorod morphology and (B) organization of CTAB and SDS micelles around the crystallites. 

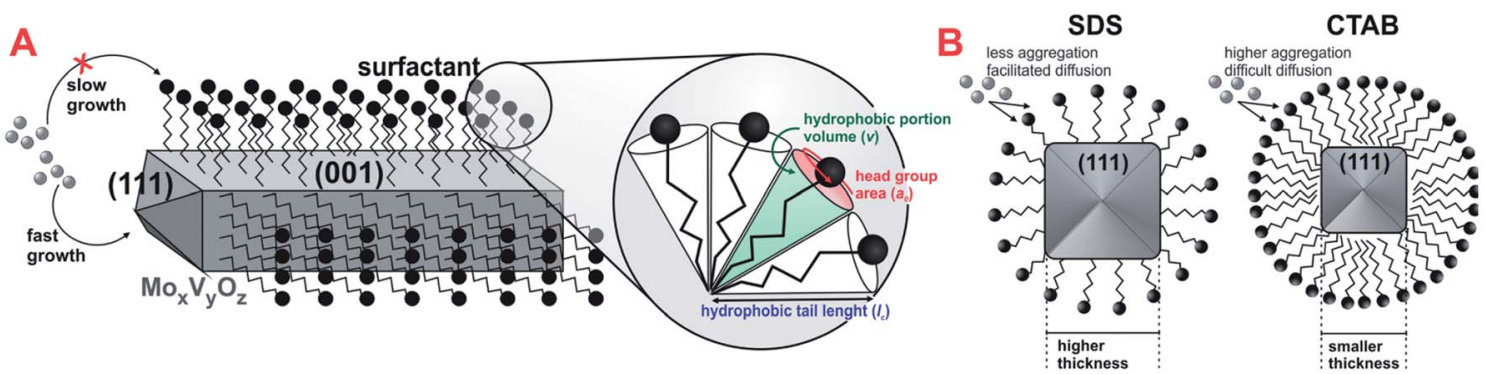

Scheme 2 (A) Representation of ionic surfactant preferentially adsorbed on the side planes of $\mathrm{Mo}_{x} \mathrm{~V}_{y} \mathrm{O}_{z}$ crystal leading the nanorod morphology and $(B)$ organization of CTAB and SDS micelles around the crystallites.

analyzing the contributions of each phase in the diffraction patterns, a consistent relation between the increasing in the crystallite size and the peak intensity ratio referent to (001) and (111) crystalline plans of $\mathrm{MoV}_{2} \mathrm{O}_{8}$ phase with the formation of nanorods was observed (see Fig. S1 $\uparrow$ and Table 1). These observations lead us to believe that the presence of surfactants are basically affecting the crystal morphology of $\mathrm{MoV}_{2} \mathrm{O}_{8}$ phase, and not considerably influencing in the formation of $\mathrm{MoO}_{3}$ and $\mathrm{Mo}_{4.65} \mathrm{~V}_{0.35} \mathrm{O}_{14}$ phases, when compared to the reference sample. The nanorod morphology were already detected and correlated to $\mathrm{MoV}_{2} \mathrm{O}_{8}$ phase in previous studies. ${ }^{33,34}$ Differences in the ratio of intensity between (001) and (111) crystalline plans are very coherent with the thickness of nanorods observed in the Fig. 2B. The catalyst CTAB-0.10, that presented the higher $I_{(001)} / I_{(111)}$ ratio have the crystallites with smaller thickness (approximately, $90 \mathrm{~nm}$ ), suggesting a fast growth in the direction of (111) facets and a limited growth in the direction normal to the side plans, like (001). The ratio $I_{(001)} / I_{(111)}$ slightly decreased for the catalyst SDS-0.10 leading to the formation nanorods with, approximately, $150 \mathrm{~nm}$ of thickness. The differences in crystal thickness in the presence of CTAB and SDS surfactants are probably associated with the limitations in the transfer of $\mathrm{Mo}-\mathrm{V}$ active phase to lateral plans due to the different aggregation of surfactant monomers to form the micelles (Scheme 2B). The aggregation number increases linearly with the increase of surfactant concentration for $\mathrm{CTAB}$ and SDS surfactants in water. ${ }^{35}$ The concentration of CTAB used in the synthesis was about 44 times the CMC, and an aggregation number above 80 is expected for this compound..$^{35}$ On the other hand, the concentration of SDS was about 6 times the CMC and an aggregation number of, approximately, 54 is expected. ${ }^{35}$ The presence of a high number of monomers in CTAB micelles are more effective in preventing the penetration of $\mathrm{Mo}-\mathrm{V}$ atoms in the sides of micelle and, consequently, the growth perpendicular to the crystal side plans, decreasing the thickness of nanorods, when compared to SDS micelles. Apparently, the presence of SDS promoted the formation of a larger amount of the $\mathrm{MoV}_{2} \mathrm{O}_{8}$ rod-like particles when compared with catalyst synthesized in the presence of CTAB, as observed by SEM images (Fig. 2B) and by increase in macroporosity, attributed to the intercrystallite spaces generated between the nanorods confirmed by Hg-porosimetry (Fig. 2A).

The XPS analyses provided information concerning the surface composition and the oxidation states of vanadium and molybdenum in the samples (Fig. S2 $\uparrow$ and Table 2). The chemical speciation showed that molybdenum oxidation state remained invariant in the samples produced by surfactantassisted synthesis compared to reference, and that $\mathrm{V}^{4+}$ was present in low quantity in all samples. According to the stoichiometry of the detected Mo and $\mathrm{V}$ crystalline phases described in Table $\mathrm{S} 1, \uparrow$ in $\mathrm{MoV}_{2} \mathrm{O}_{8}$, vanadium bears the valence $5+$. However, in $\mathrm{Mo}_{4.65} \mathrm{~V}_{0.35} \mathrm{O}_{14}$ vanadium has a mixed valence, that can be the first reason for detection of $\mathrm{V}^{4+}$ in these samples. Even presenting a mixed valence of $4^{+}$and $5+$, the low molar concentration of vanadium atoms in $\mathrm{Mo}_{4.65} \mathrm{~V}_{0.35} \mathrm{O}_{14}$ phase are not sufficient to justify the presence of $13-15 \%$ of $\mathrm{V}^{4+}$ in the samples, so some $\mathrm{V}^{4+}$ can also be present in the framework of $\mathrm{MoV}_{2} \mathrm{O}_{8}$ mixed oxide because, despite the larger atomic radius of molybdenum, the lower valence of vanadium $\left(\mathrm{V}^{4+}\right)$ makes the metal-oxygen bond distances closely similar for both elements in the $\mathrm{Mo}_{x} \mathrm{~V}_{y} \mathrm{O}_{z}$ structures, leading to its partial reduction. ${ }^{8}$ Finally, these reduced forms of vanadium could be present in small quantities of amorphous phases, not detectable by XRD but, previously reported in the synthesis of vanadiummolybdenum based mixed oxides. ${ }^{6,8,36}$ Another important fact noted is that the catalysts synthetized with surfactants showed higher quantities of O-Mo bonds compared to the reference sample, what can be associated with the higher quantities of $\mathrm{MoO}_{3}$ crystalline phase formed in these samples. The quantity of surface $\mathrm{O}-\mathrm{H}$ bonds decreased in CTAB-0.10 and SDS-0.10 samples, influencing the total acidity of these catalysts (Table 1). This observation are probably related to the decrease of surface defects on crystal surfaces formed in the presence of the surfactants. The decrease in low temperature peaks (100-200 ${ }^{\circ} \mathrm{C}$ ) of $\mathrm{NH}_{3}$-TPD profiles (Fig. $\mathrm{S} 3 \dagger$ ) observed in the CTAB-0.10 and SDS-0.10 in relation to the reference catalyst, are very coherent with the amount of surface hydroxyl bonds provided

Table 2 XPS analyses of the fresh catalysts

\begin{tabular}{|c|c|c|c|c|c|c|}
\hline \multirow[b]{2}{*}{ Catalyst } & \multicolumn{3}{|c|}{$\begin{array}{l}\text { Speciation of } \mathrm{V} \text { and Mo } \\
(\%)\end{array}$} & \multicolumn{3}{|c|}{ Surface oxygen atoms (\%) } \\
\hline & $\mathrm{V}^{4+}$ & $\mathrm{V}^{5+}$ & $\mathrm{Mo}^{6+}$ & $\mathrm{O}-\mathrm{H}$ & $\mathrm{O}-\mathrm{V}$ & O-Mo \\
\hline Reference & 15 & 85 & 100 & 10.0 & 32.4 & 57.6 \\
\hline CTAB- 0.10 & 13 & 87 & 100 & 5.0 & 30.8 & 64.2 \\
\hline SDS-0.10 & 13 & 87 & 100 & 5.6 & 21.6 & 72.8 \\
\hline
\end{tabular}


by XPS, suggesting that these peaks are related to weakly bonded ammonia adsorbed on hydroxyl groups of surface.

The results by applying the catalysts in the glycerol oxydehydration reaction are depicted in Fig. 3. The optimal reaction conditions for these materials are determined using the reference sample from our previous study. ${ }^{6}$ For comparison, the catalytic activities of pure vanadium and molybdenum oxides were determined (Fig. $\mathrm{S} 4 \dagger$ ). The $\mathrm{MoO}_{3}$ and $\mathrm{V}_{2} \mathrm{O}_{5}$ showed very low selective for acrylic acid formation, 13 and 11\%, with conversions of 95 and 98\%, and high $\mathrm{CO}_{\mathrm{x}}$ production, 72 and $70 \%$, respectively. The presence of mixed oxide phases considerably enhanced selectivity when compared to the pure oxide samples. ${ }^{6}$ The reference sample showed a gradual increase in the conversion and selectivity to acrylic acid until the fourth hour of reaction, when the conversion reached 100\%. After the fifth hour, the acrylic acid selectivity started to decrease in this sample. The catalysts prepared with surfactants presented a considerable increase in the acid acrylic formation compared to the reference sample, with selectivities of $36-45 \%$ for CTAB0.10 , and $45-57 \%$ for SDS- 0.10 catalyst. The catalysts showed a conversion of $100 \%$ with no deactivation after $6 \mathrm{~h}$ on stream and no coke was detected by elemental analysis of CNHS (not shown) or by thermogravimetry (Fig. S5†), only a weight loss in $100-200{ }^{\circ} \mathrm{C}$ range due to elimination of adsorbed water and an increase above $400{ }^{\circ} \mathrm{C}$ corresponding to the capture of molecular oxygen to site reoxidation from $\mathrm{V}^{4+}$ to $\mathrm{V}^{5+}$ were observed. Both CTAB-0.10 and SDS- 0.10 showed $100 \%$ of glycerol conversion and presented lower $\mathrm{CO}_{\mathrm{X}}$ formation when compared to the reference catalyst. The $\mathrm{CO}_{\mathrm{x}}$ production considerable decreased in the presence of CTAB- 0.10 and SDS- 0.10 catalysts with selectivities in the range of $49-53 \%$ and $36-45 \%$, respectively. It is important to note that there was a significant decrease in the amount of $\mathrm{CO}_{\mathrm{X}}$ compared to the reference sample (60-66\%). The catalyst SDS-0.10 had the best activity in terms of higher acrylic acid selectivity and low $\mathrm{CO}_{\mathrm{X}}$ formation, with $57 \%$ and $36 \%$, respectively, in the sixth hour of reaction.

The crystalline phases present in the catalysts identified before and after reaction (Fig. 4A) were carefully analyzed and quantified by Rietveld refinement (Fig. 1 and $56 \dagger$ ). Before the reaction, all catalysts showed the phases $\mathrm{Mo}_{4.65} \mathrm{~V}_{0.35} \mathrm{O}_{14}$, $\mathrm{MoV}_{2} \mathrm{O}_{8}$ and $\mathrm{MoO}_{3}$. After reaction, the formation of an additional phase, $\mathrm{MoVO}_{5}$, was observed. The presence of this phase, that contains basically reduced forms of vanadium $\left(\mathrm{V}^{4+}\right)$, is associated with the $\mathrm{V}^{5+} / \mathrm{V}^{4+}$ equilibrium established during reaction by reduction/oxidation dynamics where acrolein is oxidized into acrylic acid, generating oxygen vacancy in the catalyst structure, and subsequent filling of the vacancy with $\mathrm{O}_{2}$ as predicted by Mars-van-Krevelen mechanism. ${ }^{37}$

Significant changes were observed in the phase composition after reaction suggesting the occurrence of solid-state reactions between the single and bicomponent oxide phases. These reactions were already observed for MoVTe-based oxides in high temperatures and oxidant atmospheres. ${ }^{20}$ Considering the reference sample, $\mathrm{MoV}_{2} \mathrm{O}_{8}$ phase disappeared and molybdenum oxide phase, $\mathrm{MoO}_{3}$, considerably increased (from 15 to 30\%) in the spent catalyst. Analysing the mole percentage of vanadium, molybdenum and oxygen in the crystalline phases of fresh and spent catalysts (Fig. 4B) for reference sample, a significant decrease in the mole percentage of vanadium (from 12.6 to $2.9 \%$ ), followed by an increase in the amount of molybdenum (from 14.2 to $22.8 \%$ ) was observed. These observations strongly suggest that $\mathrm{MoV}_{2} \mathrm{O}_{8}$ is very unstable in this sample, and the most part of vanadium originally present in this mixed oxide structure is transferred to amorphous phase as shown in eqn (6). Most part of the low amount of vanadium that remained in the crystalline phase is present in the reduced phase $\mathrm{MoVO}_{5}$.

$$
\mathrm{MoV}_{2} \mathrm{O}_{8} \rightarrow \mathrm{MoO}_{3}+\mathrm{V}_{2} \mathrm{O}_{5 \text { (amorphous) }}
$$

CTAB-0.10 and SDS-0.10 catalysts showed decreases of $2.3 \%$ (from 11.7 to $9.4 \%$ ) and $0.2 \%$ (from 10.5 to $10.3 \%$ ) in the mole percentage of vanadium present in crystalline phases, respectively. The lower migration of vanadium to amorphous phase in the catalyst SDS- 0.10 , compared to CTAB- 0.10 , are probably associated with the presence of higher $\mathrm{MoV}_{2} \mathrm{O}_{8}$ phase in nanorod morphology in this sample, as observed by SEM images. In these catalysts $\mathrm{MoV}_{2} \mathrm{O}_{8}$ phase are still present after reaction, and the reduced $\mathrm{MoVO}_{5}$ phase appears as a result of the vanadium redox cycle. The percentage of $\mathrm{MoO}_{3}$ phase is considerably low in CTAB-0.10 and SDS-0.10 catalysts, suggesting a restructuration of phases according to reaction in eqn (7), where vanadium is being transferred from $\mathrm{MoV}_{2} \mathrm{O}_{8}$ to $\mathrm{MoO}_{3}$ to form $\mathrm{MoVO}_{5}$ phase and an oxygen remaining from the structure that are reacting with acrolein to produce acrylic acid. Feeding molecular oxygen to the reaction media and considering the restructuration of phases a reversible process, the $\mathrm{MoV}_{2} \mathrm{O}_{8}$

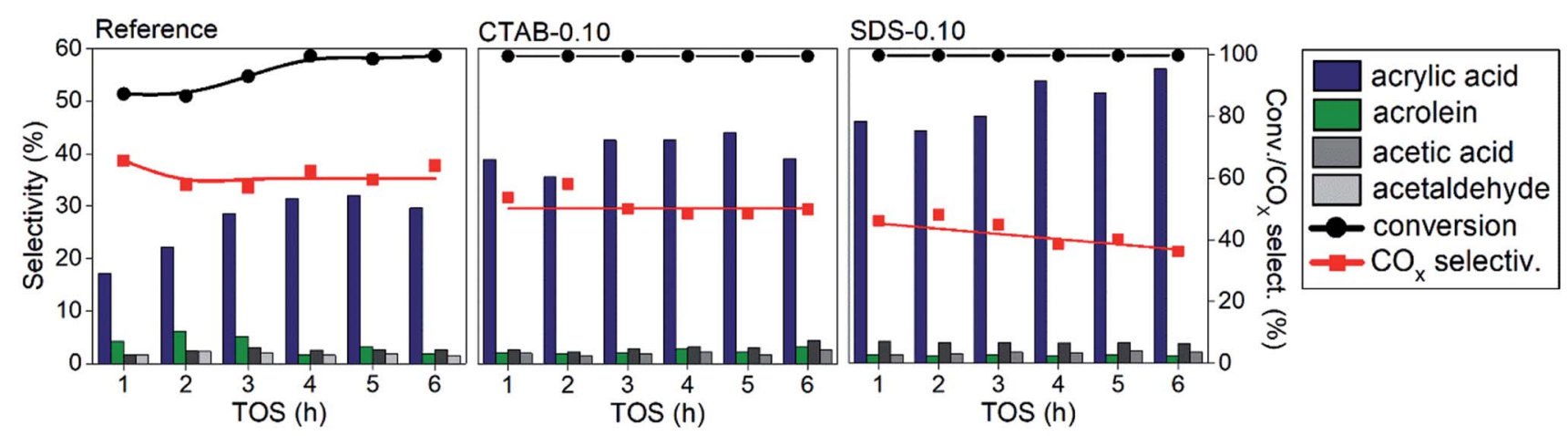

Fig. 3 Catalytic results of glycerol oxydehydration performed during $6 \mathrm{~h}$ at $320^{\circ} \mathrm{C}$ under a flow of $100 \%$ of $\mathrm{O}_{2}$. 


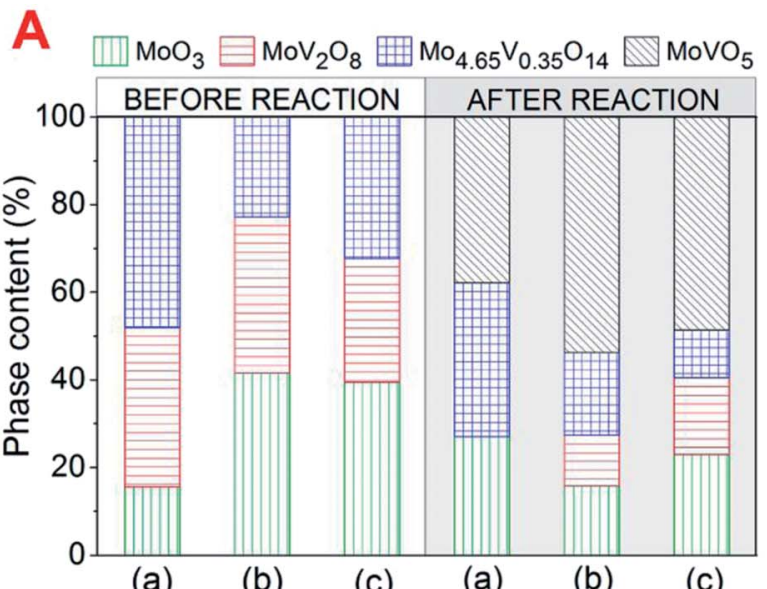

(a) (c) (a)

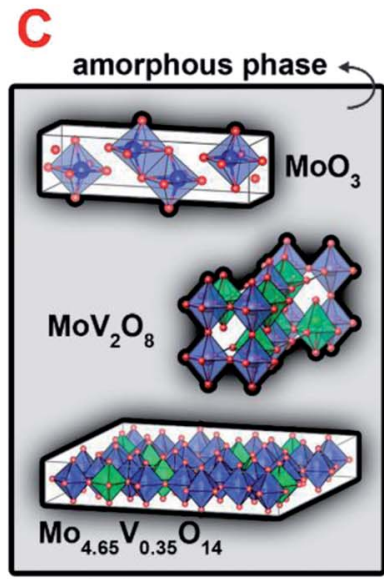

before reaction

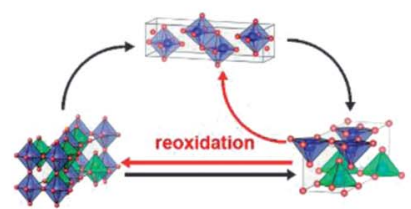

$\mathrm{MoV}_{2} \mathrm{O}_{8}+\mathrm{MoO}_{3} \rightarrow 2 \mathrm{MoVO}_{5}+[\mathrm{O}]$

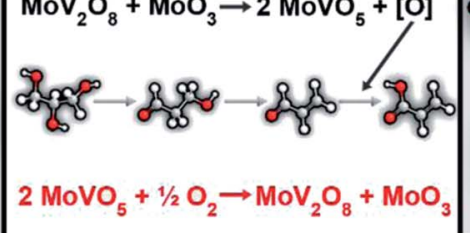

catalytic process

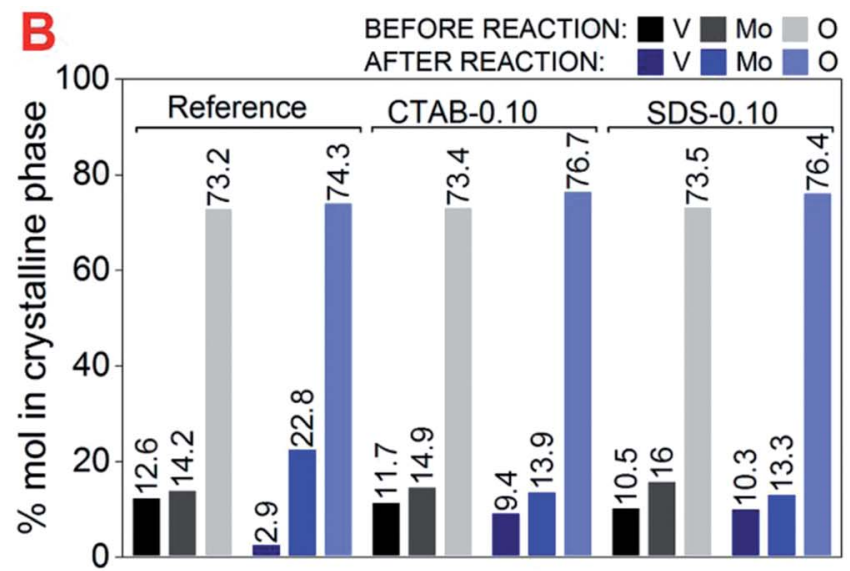

surfactant-mediated synthesis

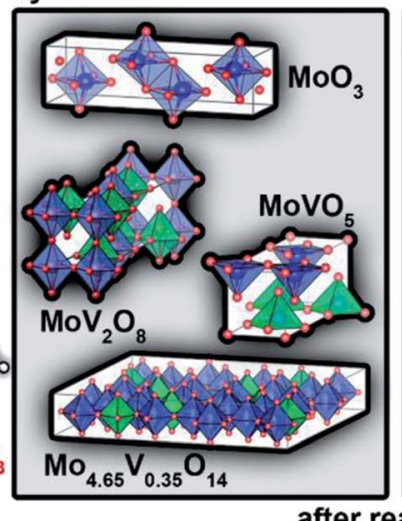

reference synthesis

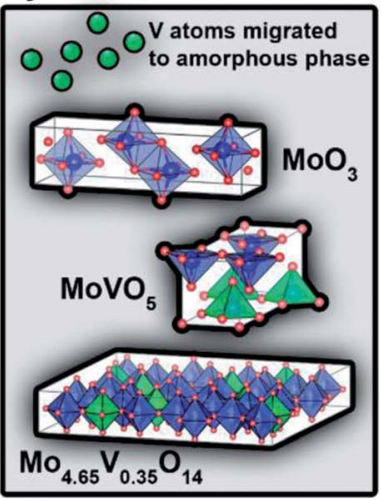

after reaction

Fig. 4 (A) Quantification of the crystalline phases determined by Rietveld refinement of fresh and spent catalysts ( $a-$ reference, $b-C T A B-0.10$ and c - SDS-0.10), (B) \% in mole of vanadium, molybdenum and oxygen present in fresh and spent catalysts calculated through Rietveld quantification (only crystalline phases identified in XRD patterns were considered in the calculation) and (C) schematic representation of modifications in the catalyst structure during catalytic reaction.

phase are being re-established as shown in eqn (8), and this cycle generates the equilibrium between $\mathrm{MoV}_{2} \mathrm{O}_{8} / \mathrm{MoVO}_{5}$ phases observed in CTAB-0.10 and SDS-0.10 spent catalysts. The decrease in acrylic acid selectivity observed for reference sample, between the fifth and sixth hour of reaction could be associated with the migration of vanadium from $\mathrm{MoV}_{2} \mathrm{O}_{8}$ crystalline phase to amorphous phase, but the presence of $\mathrm{Mo}_{4.65} \mathrm{~V}_{0.35} \mathrm{O}_{14}$ phase in the catalysts is contributing to the oxidation of acrolein during reaction, since it was already reported as active in the glycerol oxydehydration, ${ }^{38}$ and is, probably, maintaining some activity in the reference catalyst. Fig. 4C shows a schematic representation of key structural points observed for fresh and spent catalysts prepared in the presence of CTAB, SDS and in the absence of surfactant, and a proposed mechanism of phase restructuration during reaction.

$$
\begin{gathered}
\mathrm{MoV}_{2} \mathrm{O}_{8}+\mathrm{MoO}_{3} \rightarrow 2 \mathrm{MoVO}_{5}+[\mathrm{O}]_{\text {structure }} \\
2 \mathrm{MoVO}_{5}+1 / 2 \mathrm{O}_{2(\mathrm{~g})} \rightarrow \mathrm{MoV}_{2} \mathrm{O}_{8}+\mathrm{MoO}_{3}
\end{gathered}
$$

\section{Conclusions}

In summary, Mo-V mixed oxides were successfully synthetized in the absence and presence of ionic surfactants by a facile hydrothermal method and applied as catalysts in the glycerol oxydehydration to acrylic acid. Addition of surfactants in the synthesis mixture not significantly changed the nature of phases present in the catalyst but strongly influenced the crystal morphology of $\mathrm{MoV}_{2} \mathrm{O}_{8}$ phase, orienting the nucleation across specific plans during synthesis and leading to the formation of nanorod-type crystals. Rod-like morphology stabilized the $\mathrm{MoV}_{2} \mathrm{O}_{8}$ crystalline phase, favouring the redox process, through the $\mathrm{MoV}_{2} \mathrm{O}_{8} / \mathrm{MoVO}_{5}$ equilibrium, during the reaction, avoiding the migration of vanadium atoms to amorphous phase, as observed for the reference sample, resulting in a significant improvement in the performance of the catalysts. The SDS-0.10 sample achieved the best catalytic result with $100 \%$ of conversion, a maximum of $57 \%$ of selectivity to acrylic acid and a considerable decrease in $\mathrm{CO}_{\mathrm{x}}$ production from 66 to $36 \%$. 


\section{Conflicts of interest}

There are no conflicts to declare.

\section{Acknowledgements}

This work was supported by the Brazilian agencies CNPq (grant \#304698/2014-8) and FAPESP (grants \#2013/10204-2, \#2014/ 20116-6 and \#2016/10597-2). Authors also thank Dr Peter Hammer (LEFE/IQ-UNESP) for XPS measurements and data analysis.

\section{References}

1 M. Anitha, S. K. Kamarudin and N. T. Kofli, Chem. Eng. J., 2016, 295, 119.

2 B. Katryniok, S. Paul and F. Dumeignil, ACS Catal., 2013, 3, 1819.

3 L. H. Vieira, K. T. G. Carvalho, E. A. Urquieta-González, S. H. Pulcinelli, C. V. Santilli and L. Martins, J. Mol. Catal. A: Chem., 2016, 422, 148.

4 M. V. Rodrigues, C. Vignatti, T. Garetto, S. H. Pulcinelli, C. V. Santilli and L. Martins, Appl. Catal., A, 2015, 495, 84.

5 L. G. Possato, R. N. Diniz, T. Garetto, S. H. Pulcinelli, C. V Santilli and L. Martins, J. Catal., 2013, 300, 102.

6 L. F. Rasteiro, L. H. Vieira, L. G. Possato, S. H. Pulcinelli, C. V. Santilli and L. Martins, Catal. Today, 2017, 296, 10.

7 L. G. Possato, W. H. Cassinelli, T. Garetto, S. H. Pulcinelli, C. V. Santilli and L. Martins, Appl. Catal., A, 2015, 492, 243.

8 L. G. Possato, W. H. Cassinelli, C. I. Meyer, T. Garetto, S. H. Pulcinelli, C. V. Santilli and L. Martins, Appl. Catal., A, 2017, 532, 1.

9 L. H. Vieira, L. G. Possato, T. F. Chaves, S. H. Pulcinelli, C. V. Santilli and L. Martins, Mol. Catal., 2017, DOI: 10.1016/j.mcat.2017.11.027, in press.

10 P. Okoye, A. Abdullah and B. Hameed, Renewable Sustainable Energy Rev., 2017, 74, 387.

11 L. Zheng, X. Li, W. Du, D. Shi, W. Ning, X. Lu and Z. Hou, Appl. Catal., B, 2017, 203, 146.

12 D. Sun, Y. Yamada, S. Sato and W. Ueda, Green Chem., 2017, 19, 3186.

13 R. K. Grasselli and F. Trifirò, Rendiconti Lincei, 2017, 28, 59. 14 L. G. Possato, T. F. Chaves, W. H. Cassinelli, S. H. Pulcinelli, C. V Santilli and L. Martins, Catal. Today, 2016, 289, 20.

15 J. Deleplanque, J. L. Dubois, J. F. Devaux and W. Ueda, Catal. Today, 2010, 157, 351.
16 C. Doornkamp and V. Ponec, J. Mol. Catal. A: Chem., 2000, $162,19$.

17 S. Ishikawa, M. Tashiro, T. Murayama and W. Ueda, Cryst. Growth Des., 2014, 14(9), 4553.

18 S. Ishikawa, X. D. Yi, T. Murayama and W. Ueda, Catal. Today, 2014, 238, 35.

19 S. Ishikawa and W. Ueda, Catal. Sci. Technol., 2016, 6, 617.

20 L. Chen, J. Liang, W. Weng, Y. Wang, H. Wan and J. C. Védrine, Catal. Commun., 2004, 5(11), 697.

21 A. Taguchi and F. Schüth, Microporous Mesoporous Mater., 2005, 77, 1.

22 G. Leofanti, M. Padovan, G. Tozzola and B. Venturelli, Catal. Today, 1998, 41, 207.

23 J. H. de Boer, A. van den Heuvel and B. G. Linsen, J. Catal., 1964, 3, 268.

24 F. Zhao, Y.-K. Du, J.-K. Xu and S.-F. Liu, Colloid J., 2006, 68(6), 784.

25 H.-J. Butt, K. Graf and M. Kappl, Physics and Chemistry of Interfaces, Wiley-VHC Verlag GmbH \& Co. KGaA, Weinheim, Germany, 2003.

26 D. Myers, Surfactant Science and Technology, John Wiley \& Sons, Hoboken, United States, 2006.

27 W. Suprun, M. Lutecki, T. Haber and H. Papp, J. Mol. Catal. A: Chem., 2009, 309, 71.

28 B. Naik and N. N. Ghosh, Recent Pat. Nanotechnol., 2009, 3, 213.

29 J. M. Goronja, A. M. J. Ležaić, B. M. Dimitrijević and A. M. Malenović, Hem. Ind., 2016, 70, 485.

30 R. F. Ali, A. H. Nazemi and B. D. Gates, Cryst. Growth Des., 2017, 17, 4637.

31 C. Ni, P. A. Hassan and E. W. Kaler, Langmuir, 2005, 21(8), 3334.

32 M. S. Bakshi, Cryst. Growth Des., 2016, 16, 1104.

33 M. Shahid, J. Liu, Z. Ali, I. Shakir and M. F. Warsi, J. Power Sources, 2013, 230, 277.

34 Z. Yin, Y. Xiao, X. Wang, W. Wang, D. Zhao and M. Cao, Nanoscale, 2016, 8, 508.

35 M. Pisárčik, F. Devínsky and M. Pupák, Open Chem., 2015, 13, 922.

36 A. Chieregato, J. M. López Nieto and F. Cavani, Coord. Chem. Rev., 2015, 301-302, 3.

37 P. Mars and D. W. Van Krevelen, Chem. Eng. Sci., 1954, 3, 41. 38 L. Liu, B. Wang, Y. Du, Z. Zhong and A. Borgna, Appl. Catal., $B, 2015$, 174-175, 1. 